\title{
Pesticide Biomonitoring in Florida Agricultural Workers
}

\author{
Giffe T. Johnson, Steve Morris, James D. McCluskey, Ping Xu, Raymond D. Harbison \\ Center for Environmental and Occupational Risk Analysis and Management, College of Public Health, University \\ of South Florida, Tampa, USA \\ Email: gjohnson@health.usf.edu
}

Received 24 February 2014; revised 27 March 2014; accepted 23 April 2014

Copyright (C) 2014 by authors and Scientific Research Publishing Inc.

This work is licensed under the Creative Commons Attribution International License (CC BY). http://creativecommons.org/licenses/by/4.0/

c) (i) Open Access

\begin{abstract}
This descriptive study evaluates the blood serum levels of relevant pesticides in fern/ornamental and tomato agricultural workers in central and south Florida whose work activity is related to pesticide application or crop maintenance. The objectives of this study are to broadly evaluate pesticide absorption in agricultural workers, assess personal protective equipment (PPE) use and their potential relevance to pesticide absorption, and to evaluate the feasibility of using primary biomonitoring as a method of exposure assessment for long-term epidemiological investigations. Three rounds of sampling were conducted where 41 subjects provided serum samples analyzed for individual pesticides and responded to a survey regarding PPE use. Serum samples yielded quantifiable detections of DDE, Methiocarb, Malathion, Chlorpyrifos, and Endosulfan in select subjects. The personal protective equipment survey did not demonstrate association with positive serum samples. These results demonstrate that the evaluated workers are effectively protected against exposures known to result in acute toxicity. Biomonitoring for parent compounds and primary metabolites may have limited utility in long-term epidemiological studies to evaluate chronic toxicity where workers are exposed to a great diversity of workplace chemicals (fern/ornamental workers) compared to agricultural sectors where workplace chemical diversity is more limited (tomato workers).
\end{abstract}

\section{Keywords}

Pesticide Biomonitoring, Organophosphates, Organochlorines, Worker Exposure

\section{Introduction}

The use of analytical chemistry to determine the presence of toxicants in various human biological media has been a key development in the advancement of environmental and occupational risk assessment. Traditional exposure assessment methodologies are limited to the characterization of potential exposures which people may

How to cite this paper: Johnson, G.T., Morris, S., McCluskey, J.D., Xu, P. and Harbison, R.D. (2014) Pesticide Biomonitoring in Florida Agricultural Workers. Occupational Diseases and Environmental Medicine, 2, 30-38. 
encounter in their environment. Biomonitoring allows us to directly measure dose without the potential error associated with translating exposure estimates into an estimated dose.

As a result of the amount and variety of pesticides used in agriculture, there are opportunities for many workers to have pesticide exposure from activities such as planting, pesticide application, harvesting, and general maintenance activities. The breadth of potential effects from excessive exposure to "pesticides" is quite varied and depends primarily upon the individual pesticide encountered.

The most frequently cited adverse effect is neurotoxicity, which may result from acute exposure to several types of pesticides, including organophosphates, carbamates, organochlorines, some fungicides, and fumigants [1]. The potential for neurotoxicity resulting from organophosphate exposure is best characterized [1] [2]. Clinically evident cases of acute organophosphate neurotoxicity typically have symptoms including headache, dizziness, nausea, vomiting, pupillary constriction, excessive sweating, tearing, and salivation. In cases of severe poisoning, the exposed may develop muscle weakness, uncontrolled twitching, and changes in heart rate with possible progression to convulsions, coma and even death. These symptoms result from the overstimulation of postsynaptic cholinergic receptors following the inhibition of acetylcholinesterase. In addition to the previously listed sequelae, some research indicates that health effects may occur weeks after a significant organophosphate exposure and take the form of organophosphate-induced delayed polyneuropathy (OPIDP), a syndrome involving sensory abnormalities, muscle cramps, weakness, and possible paralysis. These symptoms are the consequence of axonal death following organophosphate inhibition of neuropathy target esterase [1]. There may also be long-term sequelae in addition to OPIDP, although the findings to date are controversial. Studies of individuals with a history of pesticide poisoning, either farmworkers or members of the general population, have attempted to link deficits in cognitive and psychomotor function, decreased vibration sensitivity, and impaired nerve conduction with excessive pesticide exposure long after the acute poisoning resolved [3]-[8]. Several researchers have hypothesized that heavily exposed farm workers [3] [9] [10] and termiticide applicators [11] exposed to organophosphates, malaria-control workers who sprayed DDT [12], vineyard workers exposed to fungicides [13], and fumigators exposed to methyl bromide or sulfuryl fluoride [14] [15] may have long-term deficits in psychomotor function. However, it is emerging health effects potentially related to pesticide exposure, which have yet to be well characterized that may benefit most from a biomonitoring approach.

Although the complexities associated with the toxicokinetics of various pesticides make it difficult to determine toxicity with biomonitoring outcomes, this remains a satisfactory method to draw inferences about the absorbed dose resulting from occupational pesticide exposure [16]. Multiple studies have demonstrated the utility of biomonitoring in farm worker populations who are potentially exposed to pesticides. Coronado et al. (2004) [17] compared differences in organophosphate absorption between different agricultural occupations among orchard farmers. They found that the practice of thinning (removing small buds from the limbs of trees so that the remaining buds produce larger fruit) was associated with significantly higher absorbed pesticide levels compared to workers performing other duties. In addition, the effectiveness of personal protective equipment has been successfully analyzed using biomonitoring techniques in several studies. Acquavella et al. (2004) [18] detected differences in glyphosphate levels in farm workers using different types of personal protection equipment. Similarly, other researchers [19]-[21] have evaluated farm workers with this methodology to draw inferences about the relationship between personal protective equipment usage and pesticide absorption following exposure to various pesticide species.

Despite this previous work, there remain a variety of agricultural sectors engaged in pesticide use that remain largely uncharacterized as to the absorption of those compounds used in their workplace. Clearly, there is a need to fill in the data gaps regarding the relationship between pesticide exposure/absorption in agricultural workers using a variety of pesticides, and to evaluate the use of exposure controls including personal protective equipment and administrative controls such as lock-out periods following pesticide application. The objectives of this investigation are to broadly evaluate pesticide exposure through a biomonitoring approach in fern/ornamental workers and tomato crop workers, evaluate the use of personal protective equipment in these workers, and to examine the feasibility of using a biomonitoring approach in a long-term epidemiological study to assess the relationship between low-dose pesticide exposure and chronic health effects.

\section{Methods}

\subsection{Selection of Subjects}

Two groups of Florida agricultural workers were selected for this study: 1) workers in the fern/ornamental agri- 
cultural sector including pesticide applicators and non-applicators and; 2) workers in the tomato production sector including pesticide applicators and non-applicators. Subjects were selected to participate based on the criteria that they were age 18 or greater, had participated in their normal agricultural work no more than 2 hours previous to providing a blood sample, and were capable of providing informed consent. The use of human subjects in this study was approved by the University of South Florida Institutional Review Board under IRB\#107766.

\subsection{Blood Sample Collection and Analysis}

As many non-persistent pesticides have relatively short biological half-lives (6 - 48 hours) [16], samples were collected within 2 hours following active agricultural work. Each participant provided $10 \mathrm{ml}$ of venous blood withdrawn into a lavender top tube containing EDTA, by a certified phlebotomist, registered nurse, or medical doctor. Each sample was centrifuged on site, and the separated serum was stored in snap-top vials and packed with ice for transportation to the laboratory. Samples were collected in three rounds, and each round tested for a specific pesticide set: 1) from fern/ornamental workers; 2) from tomato workers (Tomato Round 1) and; 3) an additional sampling from tomato workers (Tomato Round 2) (see Table 1).

Serum samples were analyzed for a broad panel of pesticides relevant to the subject's agricultural sector by Gas Chromatography (GC), High Performance Liquid Chromatography (HPLC), High Performance Thin Layer Chromatography (HPTLC), or Gas Chromatography Mass Spectrometry (GCMS) as appropriate for each compound analyzed. The analytes, method detection limits, and relevant subject classification can be found in Table 1.

\subsection{Personal Protection Equipment Survey}

Participants were asked to provide information by written questionnaire regarding their use of personal protective equipment on the same work day as blood sample collection took place. The survey was offered in either English or Spanish, depending on participant preference. The questionnaire asked workers if they wore eye protection, facial protection, a mask or respirator of any type, gloves of any type, arm protection (long sleeves), leg protection (long pants), foot protection (close toed shoes), or a plastic or rubber suit.

\subsection{Data Analysis}

This descriptive study provides all quantitative results from blood sample analysis and summary statistics in tabulated form. Survey PPE data was tested for independence comparing PPE usage between pesticide applicators and non-applicators using Fisher's Exact Test for right-sided probability. P-values less than 0.05 were considered statistically significant. All data analysis was performed with SAS 9.4.

\section{Results}

A total of 41 subjects participated in this study, including 18 fern/ornamental workers and 23 tomato workers. Subjects were all male, aged 18 - 64, with 65\% self-reporting as Hispanic/Latino and the remaining $35 \%$ reporting no ethnicity.

\subsection{Fern/Ornamental Workers}

Surveyed workers in the Fern/Ornamental sector consisted of 9 pesticide applicators and 9 non-applicators. Due to the wide variety of pesticides used in this industry, the blood samples for this class of subjects were analyzed for 39 individual pesticides and primary metabolites (Table 2). Of these analyses only DDE, a primary metabolite of DDT was measured at detectable levels. Detection of DDE was distributed evenly between pesticide applicators and non-applicators. In subjects with detectable amounts, the range of concentrations among pesticide applicators was 1.4 - 14 ppb DDE and among non-applicators concentrations ranged 2.1 - 42 ppb DDE. Pesticide applicators more often reported PPE use compared to non-applicators in every category surveyed, with significant differences in the categories of face protection, respirator/mask use, and long pants.

\subsection{Tomato Workers Round 1 Sampling}

The first round of sampling in tomato workers consisted of 8 pesticide applicators and 8 non-applicators. This 
Table 1. Pesticide analytes measured in blood samples classified by subject group each analysis was performed on, including method detection limit and reporting units.

\begin{tabular}{|c|c|c|}
\hline Pesticide & Method Detection Limit & Subject Group Tested \\
\hline Azinphos-Methyl & $0.30 \mathrm{ug} / \mathrm{ml}$ & Fern/Ornamental \\
\hline Carbophention & $0.30 \mathrm{ug} / \mathrm{ml}$ & Fern/Ornamental \\
\hline Chlorpyrifos & $0.30 \mathrm{ug} / \mathrm{ml}$ & Fern/Ornamental \\
\hline Coumaphos & $0.30 \mathrm{ug} / \mathrm{ml}$ & Fern/Ornamental \\
\hline Diazinon & $0.30 \mathrm{ug} / \mathrm{ml}$ & Fern/Ornamental \\
\hline Dichlorvos & $0.30 \mathrm{ug} / \mathrm{ml}$ & Fern/Ornamental \\
\hline Dimethoate & $0.30 \mathrm{ug} / \mathrm{ml}$ & Fern/Ornamental \\
\hline EPN & $0.30 \mathrm{ug} / \mathrm{ml}$ & Fern/Ornamental \\
\hline Ethion & $0.30 \mathrm{ug} / \mathrm{ml}$ & Fern/Ornamental \\
\hline Fenchlorphos & $0.30 \mathrm{ug} / \mathrm{ml}$ & Fern/Ornamental \\
\hline Fenthion & $0.30 \mathrm{ug} / \mathrm{ml}$ & Fern/Ornamental \\
\hline Fonofos & $0.30 \mathrm{ug} / \mathrm{ml}$ & Fern/Ornamental \\
\hline Malathion & $0.30 \mathrm{ug} / \mathrm{ml}$ & Fern/Ornamental \\
\hline Metasystox & $0.30 \mathrm{ug} / \mathrm{ml}$ & Fern/Ornamental \\
\hline Methyl Parathion & $0.30 \mathrm{ug} / \mathrm{ml}$ & Fern/Ornamental \\
\hline Mevinphos & $0.30 \mathrm{ug} / \mathrm{ml}$ & Fern/Ornamental \\
\hline p-Nitrophenol & $0.30 \mathrm{ug} / \mathrm{ml}$ & Fern/Ornamental \\
\hline Parathion & $0.30 \mathrm{ug} / \mathrm{ml}$ & Fern/Ornamental \\
\hline Paraoxon & $0.30 \mathrm{ug} / \mathrm{ml}$ & Fern/Ornamental \\
\hline Phorate & $0.30 \mathrm{ug} / \mathrm{ml}$ & Fern/Ornamental \\
\hline Terbufos & $0.30 \mathrm{ug} / \mathrm{ml}$ & Fern/Ornamental \\
\hline DDE & $1.0 \mathrm{ppb}$ & Fern/Ornamental \\
\hline Lindane & $1.0 \mathrm{ppb}$ & Fern/Ornamental \\
\hline Alpha-Chlordane & $1.0 \mathrm{ppb}$ & Fern/Ornamental \\
\hline Gamma-Chlordane & $1.0 \mathrm{ppb}$ & Fern/Ornamental \\
\hline Oxychlordane & $1.0 \mathrm{ppb}$ & Fern/Ornamental \\
\hline Trans-Nonachlor & $1.0 \mathrm{ppb}$ & Fern/Ornamental \\
\hline Heptachlor & $1.0 \mathrm{ppb}$ & Fern/Ornamental \\
\hline Hepatachlorepoxide & $1.0 \mathrm{ppb}$ & Fern/Ornamental \\
\hline DDT & $1.0 \mathrm{ppb}$ & Fern/Ornamental \\
\hline Hexachlorobenzene & $1.0 \mathrm{ppb}$ & Fern/Ornamental \\
\hline Dieldrin & $1.0 \mathrm{ppb}$ & Fern/Ornamental \\
\hline Methoxychlor & $1.0 \mathrm{ppb}$ & Fern/Ornamental \\
\hline DDD & $1.0 \mathrm{ppb}$ & Fern/Ornamental \\
\hline Bendiocarb & $0.10 \mathrm{ug} / \mathrm{ml}$ & Fern/Ornamental \\
\hline
\end{tabular}




\begin{tabular}{ccl} 
Continued & & \\
\cline { 2 - 3 } Carbaryl & $0.10 \mathrm{ug} / \mathrm{ml}$ & Fern/Ornamental \\
Sarbofuran & $0.10 \mathrm{ug} / \mathrm{ml}$ & Fern/Ornamental \\
1 -Naphthol & $0.10 \mathrm{ug} / \mathrm{ml}$ & Fern/Ornamental \\
Propoxur & $0.20 \mathrm{ug} / \mathrm{ml}$ & Fern/Ornamental \\
Carbaryl & $0.01 \mathrm{ug} / \mathrm{ml}$ & Tomato Round 1 \\
Methiocarb & $0.01 \mathrm{ug} / \mathrm{ml}$ & Tomato Round 1 \\
Malathion & $0.01 \mathrm{ug} / \mathrm{ml}$ & Tomato Round 1 \\
Chlorpyrifos & $0.01 \mathrm{ug} / \mathrm{ml}$ & Tomato Round 1 \\
Chlorfenvinphos & $0.01 \mathrm{ug} / \mathrm{ml}$ & Tomato Round 1 \\
Endosulfan & $1.0 \mathrm{ng} / \mathrm{ml}$ & Tomato Round 2 \\
Esfenvalerate & $1.0 \mathrm{ng} / \mathrm{ml}$ & Tomato Round 2 \\
\hline
\end{tabular}

\begin{tabular}{cccc} 
Table 2. Results for sampling among fern/ornamental workers. & & \\
\hline Total & Non-Applicators & Pesticide Applicators & p-Value \\
\hline DDE Detects & 9 & 9 & \\
Eye Protection & 1 & 6 & \\
Face Protection & 0 & 3 & 0.2882 \\
Respirator Protection & 0 & 6 & 0.0045 \\
Hand Protection & 5 & 6 & 0.0045 \\
Arm Protection & 3 & 6 & 0.5000 \\
Leg Protection & 2 & 6 & 0.1735 \\
Feet Protection & 7 & 8 & 0.0076 \\
Rubber/Plastic Suit & 1 & 9 & 0.2353 \\
\hline
\end{tabular}

round of sampling analyzed 5 pesticides (Table 1), of which methiocarb, malathion, and chlorpyrifos were detectable in subjects classified as pesticide applicators. In a single subject, methiocarb was measured at 0.029 $\mathrm{ug} / \mathrm{ml}$ serum and malathion was measured at $0.010 \mathrm{ug} / \mathrm{ml}$ serum. This subject reported using complete protection, including a rubber suit and a respirator. In one other subject, chlorpyrifos was detected at $0.010 \mathrm{ug} / \mathrm{ml}$. This subject reported minimal PPE use, including no respirator and no rubber suit. With the exception of the use of gloves (which was equivalent), pesticide applicators had higher reported use of PPE than non-applicators, although the only significant finding was increased use of close toed shoes among pesticide applicators. No pesticides were detected in non-applicator blood analyses (Table 3).

\subsection{Tomato Workers Round 2 Sampling}

The second round of sampling in tomato workers consisted of 4 pesticide applicators and 3 non-applicators. This round of sampling analyzed for 2 pesticides (Table 4), of which endosulfan was detectable in the blood sample of a single pesticide applicator at a concentration of $1.06 \mathrm{ng} / \mathrm{ml}$ serum. This subject reported using full protection, including a respirator and a rubber or plastic suit. During this round of surveying, PPE use by pesticide applicators was either equivalent to or more highly reported compared to non-applicators, though the small sample size prevented robust statistical analysis. 
Table 3. Results for the first round of sampling among tomato workers.

\begin{tabular}{cccc}
\hline & Non-Applicators & Pesticide Applicators & p-Value \\
\hline Total & 8 & 8 & \\
Methiocarb Detects & 0 & 1 & \\
Malathion Detects & 0 & 1 & \\
Chlorpyrifos Detects & 0 & 1 & \\
Eye Protection & 5 & 5 & 0.6958 \\
Face Protection & 3 & 6 & 0.1573 \\
Respirator Protection & 2 & 5 & 0.1573 \\
Hand Protection & 6 & 6 & 0.7154 \\
Arm Protection & 2 & 5 & 0.1573 \\
Leg Protection & 4 & 7 & 0.1410 \\
Feet Protection & 4 & 8 & 0.0385 \\
Rubber/Plastic Suit & 0 & 3 & 0.1000 \\
\hline
\end{tabular}

Table 4. Results for the second round of sampling among tomato workers.

\begin{tabular}{cccc}
\hline & Non-Applicators & Pesticide Applicators & p-Value \\
Total & 3 & 4 & $*$ \\
Endosulfan Detects & 0 & 1 & 1.0000 \\
Eye Protection & 3 & 4 & 0.7143 \\
Face Protection & 3 & 3 & $*$ \\
Respirator Protection & 2 & 3 & 0.7143 \\
Hand Protection & 3 & 4 & $*$ \\
Arm Protection & 2 & 3 & $*$ \\
Leg Protection & 3 & 4 & 0.6286 \\
Feet Protection & 3 & 4 & 2 \\
Rubber/Plastic Suit & 1 & & $*$ \\
\hline
\end{tabular}

${ }^{*}$ Insufficient negative responses for statistical analysis.

\section{Discussion}

Our principal goal in this study was to evaluate the feasibility of conducting pesticide biomonitoring using blood serum as a biological media. Our results indicate that this method is feasible under certain conditions and may be enhanced with increasingly structured sampling protocols. Two features determine the feasibility of this method: 1) that analytical equipment and analytical protocols be available to quantify chemical pesticide levels at or below a $1 \mathrm{ng} / \mathrm{ml}$ detection limit; and 2) that access to workers can be targeted to periods of activity that result in the greatest exposure periods of concern as well as during exposure lows in order to accurately characterize long term exposure. Despite the limitations of this study, including low sample size and moderate sensitivity for most analytical methods, the data demonstrates the utility of this approach under appropriate circumstances.

Of the pesticide applicators and other agricultural workers we evaluated, we did not find any evidence of pesticide exposures that could result in acute toxicity. The measured concentrations of DDE are not likely to be occupationally related as DDT (the parent compound of DDE) is no longer used in this occupational setting. DDE is a metabolite of DDT that is slowly produced as the lipid stored DDT compound is metabolized over a period 
of years. As well, the levels measured here are concordant with background levels found in the Second National Health and Nutrition Examination Survey (NHANES II), which found that of 5994 persons, DDE was detected in the serum of $99.5 \%$ of persons with a median level of $12.6 \mathrm{ppb}$, ranging from 0 - $379 \mathrm{ppb}$ [22]. The presence of DDE, in the absence of detectable DDT, indicates an older exposure, perhaps even from time spent in another nation that continues to use DDT as an insecticide.

However, the detection of methiocarb, malathion, chlorpyrifos, and endosulfan at serum levels below $1 \mathrm{ug} / \mathrm{ml}$ are likely occupationally relevant findings. Interestingly, the participants from whom these samples were taken did not report using those particular pesticides the day the blood sample was drawn. This indicates two potentially interesting phenomena in terms of sources of worker exposure: 1) the workers may not have had knowledge of the pesticide(s) they were applying that day; or 2) the workers may have used equipment that was not properly decontaminated resulting in a secondary exposure. With the exception of endosulfan, all of these detected pesticides are non-persistent, and have short biological half-lives. It is therefore unlikely that the measured pesticide levels indicate an older exposure, with the exception of endosulfan, whose biological persistence would make the detection of older exposures possible.

The biological monitoring performed in this investigation (at current levels of detection) would also be extremely useful for determining failures in preventative measures, such as lack of PPE use or ineffective PPE fit, though our results did not demonstrate evidence that these conditions were present for the workers we sampled. However, ornamentals industry requires the care of many different plant species, which have various care and pesticide needs. As a result, the workers in this environment may be especially difficult to perform biological monitoring with, as the analyte panel would need to correspond with the specific type of pesticide being used in the workplace at the time of sampling. While the results of this investigation do not indicate any harmful exposure is occurring in workers in the ferns/ornamental agricultural sector, a biological monitoring program would need to analyze a multitude of pesticide related chemicals at extremely low levels over a long period of time to accurately characterize long-term exposure. This type of program would perhaps be cost prohibitive. A weakness of the current study is the low sample size; recruiting a larger cohort for more robust analysis would further increase costs. A potential solution is to conduct preliminary biomonitoring to develop a job specific exposure matrix, providing a lower cost estimate of exposure that retains a basis in experimentally derived data collection.

In a population of workers that focus on a specific crop, such as pesticide applicators working in the tomato industry, the range of pesticide related chemicals may be less diverse and more manageable for biological monitoring. Tomato workers continue to work with several pesticides that have poorly characterized health outcomes following chronic, low level exposure, including endosulfan, a persistent organochlorine pesticide. Agricultural workers in the tomato industry will likely be a target population for future research, given that their pesticide exposure spectrum is more manageable from a biomonitoring perspective, and are likely to produce more robust data. Further high resolution data for low level pesticide exposures is needed to adequately characterize any health effects that may occur from chronic exposure and to identify and correct currently unprotected pathways of exposure.

\section{Conclusion}

This study evaluated the blood serum levels of relevant pesticides in fern/ornamental and tomato agricultural workers in central and south Florida whose work activity is related to pesticide application or crop maintenance. We attempted to broadly evaluate pesticide absorption in agricultural workers, assess PPE use and their potential relevance to pesticide absorption, and to evaluate the feasibility of using primary biomonitoring as a method of exposure assessment for long-term epidemiological investigations. Of the pesticide applicators and other agricultural workers we evaluated, we did not find any evidence of pesticide exposures that could result in acute toxicity. Long-term pesticide biomonitoring via blood sample may be feasible for providing longitudinal exposure data for epidemiological investigations, but will require the commitment of substantial resources.

\section{Acknowledgements}

The authors thank the Farmworker Association of Florida (FWAF) for assisting in community outreach to recruit subjects for participation in this study. This study was funded in part by the NIOSH Southeast Center for Agricultural Health and Injury Prevention Grant \# UKRF 3048105180-09-432 and the NIOSH Sunshine ERC Grant \#6402103350. 


\section{References}

[1] Keifer, M. and Mahurin, R. (1997) Chronic Neurologic Effects of Pesticide Overexposure. Occupational Medicine, 12, 291-304.

[2] He, F. (2000) Neurotoxic Effects of Insecticides-Current and Future Research: A Review. Neurotoxicology, 21, 829835.

[3] London, L., Myers, J.E., Nell, V., Taylor, T. and Thompson, M.L. (1997) An Investigation into Neurologic and Neurobehavioral Effects of Long-Term Agrichemical Use among Deciduous Fruit Farm Workers in the Western Cape, South Africa. Environmental Research, 73, 132-145. http://dx.doi.org/10.1006/enrs.1997.3715

[4] McConnell, R., Keifer, M. and Rosenstock, L. (1994) Elevated Quantitative Vibrotactile Threshold among Workers Previously Poisoned with Methamidophos and Other Organophosphate Pesticides. American Journal of Industrial Medicine, 25, 325-334. http://dx.doi.org/10.1002/ajim.4700250303

[5] Ohayo-Mitoko, G.J., Kromhout, H., Simwa, J.M., Boleij, J.S. and Heederik, D. (2000) Self Reported Symptoms and Inhibition of Acetylcholinesterase Activity among Kenyan Agricultural Workers. Occupational and Environmental Medicine, 57, 195-200. http://dx.doi.org/10.1136/oem.57.3.195

[6] Stokes, L., Stark, A., Marshall, E. and Narang, A. (1995) Neurotoxicity among Pesticide Applicators Exposed to Organophosphates. Occupational and Environmental Medicine, 52, 648-653. http://dx.doi.org/10.1136/oem.52.10.648

[7] Savage, E., Keefe, T.J., Mounce, L.M., Heaton, R.K., Lewis, J.A. and Burcar, P.J. (1988) Chronic Neurological Sequelae of Acute Organophosphate Pesticide Poisoning. Archives of Environmental Health, 43, 38-45. http://dx.doi.org/10.1080/00039896.1988.9934372

[8] Steenland, K., Jenkins, B., Ames, R.G., O’Malley, M., Chrislip, D. and Russo, J. (1994) Chronic Neurological Sequelae to Organophosphate Pesticide Poisoning. American Journal of Public Health, 84, 731-736. http://dx.doi.org/10.2105/AJPH.84.5.731

[9] Daniell, W., Barnhart, S., Demers, P., Costa, L.G., Eaton, D.L., Miller, M., et al. (1992) Neuropsychological Performance among Agricultural Pesticide Applicators. Environmental Research, 59, 217-228. http://dx.doi.org/10.1016/S0013-9351(05)80241-5

[10] Gomes, J., Lloyd, O.L. and Revitt, D.M. (1999) The Influence of Personal Protection, Environmental Hygiene and Exposure to Pesticides on the Health of Immigrant Farm Workers in a Desert Country. International Archives of Occupational and Environmental Health, 72, 40-45. http://dx.doi.org/10.1007/s004200050332

[11] Steenland, K., Dick, R.B., Howell, R.J., Chrislip, D.W., Hines, C.J., Reid, T.M., et al. (2000) Neurologic Function among Termiticide Applicators Exposed to Chlorpyrifos. Environmental Health Perspectives, 108, 293-300. http://dx.doi.org/10.1289/ehp.00108293

[12] van Wendel de Joode, B., Wesseling, C., Kromhout, H., Monge, P., et al. (2001) Chronic Nervous-System Effects of Long-Term Occupational Exposure to DDT. Lancet, 357, 1014-1016. http://dx.doi.org/10.1016/S0140-6736(00)04249-5

[13] Baldi, I., Filleul, L., Mohammed-Brahim, B., Fabrigoule, C., Dartigues, J., et al. (2001) Neuropsychologic Effects of Long-Term Exposure to Pesticides: Results from the French Phytoner Study. Environmental Health Perspectives, 109, 839-844. http://dx.doi.org/10.1289/ehp.01109839

[14] Anger, W., Moody, L., Burg, J., Brightwell, W.S., Taylor, B.J., et al. (1986) Neurobehavioral Evaluation of Soil and Structural Fumigators Using Methyl Bromide and Sulfuryl Fluoride. Neurotoxicology, 7, 137-156.

[15] Calvert, G.M., Mueller, C.A., Fajen, J.M., Chrislip, D.W., Russo, J., et al. (1998) Health Effects Associated with Sulfuryl Fluoride and Methyl Bromide Exposure among Structural Fumigation Workers. American Journal of Public Health, 88, 1774-1780. http://dx.doi.org/10.2105/AJPH.88.12.1774

[16] Barr, D.B., Thomas, K., Curwin, B., Landsittel, D., Raymer, J., Lu, C., Donnelly, K.C. and Acquavella, J. (2006) Biomonitoring of Exposure in Farmworker Studies. Environmental Health Perspectives, 114, 936-942. http://dx.doi.org/10.1289/ehp.8527

[17] Coronado, G.D., Thompson, B., Strong, L., Griffith, W.C. and Islas, I. (2004) Agricultural Task and Exposure to Organophosphate Pesticides among Farmworkers. Environmental Health Perspectives, 112, 142-147. http://dx.doi.org/10.1289/ehp.6412

[18] Acquavella, J.F., Alexander, B.H., Mandel, J.S., Gustin, C., Baker, B., Chapman, P. and Bleeke, M. (2004) Glyphosate Biomonitoring for Farmers and Their Families: Results from the Farm Family Exposure Study. Environmental Health Perspectives, 112, 321-326. http://dx.doi.org/10.1289/ehp.6667

[19] Arbuckle, T.E., Burnett, R., Cole, D., Teschke, K., Dosemeci, M., Bancej, C. and Zhang, J. (2002) Predictors of Herbicide Exposure in Farm Applicators. International Archives of Occupational and Environmental Health, 75, 406-414. 
http://dx.doi.org/10.1007/s00420-002-0323-7

[20] Arcury, T.A., Quandt, S.A., Rao, P., Barr, D.B. and Hoppin, J.A. (2005) Organophosphate Pesticide Metabolite Levels among Farmworker Family Members in Western North Carolina: Case Comparisons. Human Organization, 64, 40-51.

[21] Hines, C.J. and Deddens, J.A. (2001) Determinants of Chlorpyrifos Exposures and Urinary 3,5,6-Trichloro-2-pyridinol Levels among Termiticide Applicators. Annals of Occupational Hygiene, 45, 309-321. http://dx.doi.org/10.1093/annhyg/45.4.309

[22] CDC (2003) National Health and Nutrition Examination Survey. National Center for Health Statistics, Hyattsville. http://www.cdc.gov/nchs/nhanes.htm 